NBER WORKING PAPER SERIES

DO CALL CENTERS PROMOTE SCHOOL ENROLLMENT? EVIDENCE FROM
INDIA

Emily Oster

M. Bryce Millett

Working Paper 15922

http://www.nber.org/papers/w15922

\author{
NATIONAL BUREAU OF ECONOMIC RESEARCH \\ 1050 Massachusetts Avenue \\ Cambridge, MA 02138 \\ April 2010
}

Seema Jayachandran, Robert Jensen, Larry Katz, Andrei Shleifer and participants in seminars at the University of Chicago provided helpful comments. We are grateful to Perwinder Singh for excellent research assistance. The views expressed herein are those of the authors and do not necessarily reflect the views of the National Bureau of Economic Research.

NBER working papers are circulated for discussion and comment purposes. They have not been peerreviewed or been subject to the review by the NBER Board of Directors that accompanies official NBER publications.

(C) 2010 by Emily Oster and M. Bryce Millett. All rights reserved. Short sections of text, not to exceed two paragraphs, may be quoted without explicit permission provided that full credit, including $\odot$ notice, is given to the source. 
Do Call Centers Promote School Enrollment? Evidence from India

Emily Oster and M. Bryce Millett

NBER Working Paper No. 15922

April 2010

JEL No. I21,J21,J24

\begin{abstract}
$\underline{\text { ABSTRACT }}$
Over the last two decades in India there have been large increases in outsourced jobs and large increases in schooling rates, particularly in English. Existing evidence suggests the trends are broadly related. In this paper we explore how localized these impacts are; this has implications for understanding how quickly information about these jobs diffuses. We use panel data on school enrollment from a comprehensive school-level administrative dataset. This is merged with detailed data on Information Technology Enabled Services (ITES) center location and founding dates. Using school fixed effects, we estimate the impact of introducing a new ITES center in the vicinity of the school on enrollment. We find that introducing a new ITES center results in a 5.7\% increase in number of children enrolled; these effects are extremely localized. We argue this result is not driven by pre-trends in enrollment or endogenous center placement, and is not a result of ITES-center induced changes in population or increases in income. The effect is driven entirely by English-language schools, consistent with the claim that the impacts are driven by changes in returns to schooling.
\end{abstract}

\author{
Emily Oster \\ University of Chicago \\ Booth School of Business \\ 5807 South Woodlawn Ave \\ Chicago, IL 60637 \\ and NBER \\ eoster@uchicago.edu \\ M. Bryce Millett \\ 5541 S Everett Ave \\ Chicago, IL \\ 60637 \\ mbmillett@gmail.com
}




\title{
Do Call Centers Promote School Enrollment? Evidence from India
}

\author{
Emily Oster* \\ University of Chicago and NBER \\ emily.oster@chicagobooth.edu
}

\author{
Bryce Millett \\ University of Chicago \\ mbmillett@gmail.com
}

Draft: April 13, 2010

\begin{abstract}
Over the last two decades in India there have been large increases in outsourced jobs and large increases in schooling rates, particularly in English. Existing evidence suggests the trends are broadly related. In this paper we explore how localized these impacts are; this has implications for understanding how quickly information about these jobs diffuses. We use panel data on school enrollment from a comprehensive school-level administrative dataset. This is merged with detailed data on Information Technology Enabled Services (ITES) center location and founding dates. Using school fixed effects, we estimate the impact of introducing a new ITES center in the vicinity of the school on enrollment. We find that introducing a new ITES center results in a $5.7 \%$ increase in number of children enrolled; these effects are extremely localized. We argue this result is not driven by pre-trends in enrollment or endogenous center placement, and is not a result of ITES-center induced changes in population or increases in income. The effect is driven entirely by English-language schools, consistent with the claim that the impacts are driven by changes in returns to schooling.
\end{abstract}

\section{Introduction}

In 1991, roughly 56,000 individuals were employed in outsourcing-related businesses in India; by 2010, this figure had increased to 2.3 million (NASSCOM, 2004; NAASCOM, 2010). Over roughly the same time period, from 1991 to 2006, the share of children completing primary school increased from $64 \%$ to $86 \%$ (World Bank, 2009). In recent years parts of India have also seen a dramatic increase in English language schooling: in Andra Pradesh, for example, the share of primary school students enrolled in English-language schooling increased from 12 percent to 24 percent between 2002 and 2007.

Perhaps not surprisingly, these trends appear to be connected. Outsourced jobs pay high wages, but demand employees with high levels of education and, typically, a good command of

${ }^{*}$ Seema Jayachandran, Robert Jensen, Larry Katz, Andrei Shleifer and participants in seminars at the University of Chicago provided helpful comments. We are grateful to Perwinder Singh for excellent research assistance. 
English. Munshi and Rozensweig (2006) show evidence that the return to English-language schooling in Bangalore tripled between 1980 to 2000; over the same period, English-language school enrollment increased among groups best able to take advantage of the new jobs. Similarly, Shastry (2010) shows evidence that the wage returns to schooling increase over the 1990s in districts with more IT growth; over this same period, school enrollment also increases. This evidence on India echoes a much larger literature on the general relationship between returns to education and school enrollment (see, among many others, Freeman, 1976; Katz and Murphy, 1992; Heckman, 1993; Kane, 1994; Foster and Rozensweig, 1996; Griliches, 1997).

An important related issue is how fast and geographically broad these responses are. In the Indian context, simple calculations suggest that mobility among educated people is fairly high: roughly $30 \%$ of individuals with a high school degree or more end up living and working somewhere different than where they grew up. This high mobility means that changes in job opportunities will influence returns to schooling over a relatively broad geographic area. However, knowledge about these changes may be limited if information travels slowly. To the extent this is the case, changes in job opportunities may have disproportionate impacts on very local areas. Understanding the extent to which responses are localized may be valuable for understanding how concentrated the education and welfare gains to these changes will be, and may also speak to the value of policies which increase information about returns to schooling (as in Jensen, 2009).

In this paper, we address this question using a rich new dataset. We begin with panel data on enrollment at the school level from a comprehensive administrative dataset in three states in India (Karnataka, Andra Pradesh and Tamil Nadu); each school is observed for a period of four to eight years over the early 2000s. We merge these data with a newly collected dataset on Information Technology Enabled Services (ITES) business locations and founding dates 1 Our ITES center location data allows us to identify the PIN code (similar to a zip code) location of each center, which we can link to school location. We use an estimator with school fixed effects to estimate how enrollment changes within an individual school upon the introduction of a new ITES center to the area. The relatively long panel will allow us to effectively rule out concerns that our results are driven by omitted variables or pre-existing trends, allowing us to make stronger causal claims than the existing literature about the IT-schooling link. Our data also includes information on school

\footnotetext{
${ }^{1}$ We focus on areas outside of the major cities of Chennai, Bangalore and Hyderabad where outsourcing businesses are so common that it is unrealistic to consider the introduction of such businesses as representing a change in job options.
} 
language of instruction, which will allow us to estimate whether effects differ for English and non-English language schools.

We begin at the smallest geographic level, estimating the impact of ITES center introduction on schools in the same PIN code as the ITES center. A PIN code is similar in size to a village or (in more urban areas) a city neighborhood. We find strong positive effects which occur very quickly: the introduction of one additional ITES center to the PIN code is associated with a $5.5 \%$ increase in number of children enrolled in the school in the year after the center introduction 2 Our primary regressions control for school fixed effects, several time-varying school infrastructure controls and year fixed effects interacted with state dummies and several village-level correlates of ITES center introduction. Our effects are robust to controlling for district specific trends, and are similar if we restrict to areas with English-language schools (these areas are more likely to get ITES centers) or to areas which ever have ITES centers during the sample period. They are of similar magnitude but slightly less precise if we look at whether the area has any ITES centers, rather than the number.

Our central results focus on the impact of ITES centers in the immediate vicinity (i.e. the school's own PIN code). In a secondary set of results we explore the impact of ITES centers in neighboring PIN codes, which will give us a sense of how localized the impacts are. We define two new variables: number ITES centers in the two closest PIN codes (an average of 2.3 miles away from the local PIN code) and number of ITES centers in the 3rd to 5th closest neighbors (an average of 4.6 miles away) ${ }^{3}$ ITES centers in the two closest neighboring PIN codes also have a positive impact on school enrollment, but it is smaller and less significant than the own-PIN code effects. The slightly further ITES centers have no impact. This suggests that the effects are extremely localized; they do not extend to ITES centers even a few miles away.

The primary issue with interpreting these results as showing a causal relationship between ITES centers in the PIN code and school enrollment is the possibility of pre-trends. The inclusion of school fixed effects in our specification addresses the concern that ITES center introduction is associated with some fixed area characteristic, but they do not address the concern that ITES centers might be introduced to areas which are changing more rapidly 4 To address this, we look

\footnotetext{
${ }^{2}$ Based on other data (the National Family and Health Survey) enrollment rate in this period is around $75 \%$ at primary-school ages. Given this, our results imply about a 4.1 percentage point increase in enrollment rate.

${ }^{3}$ We define distances using GIS data on PIN codes; the GIS data gives the location of the post office for that PIN code. When we report distances, we therefore report the distance between the post offices in neighboring PIN codes.

${ }^{4}$ We should note that we have no reason to think this type of endogenous placement is common. Conversations with
} 
directly for pre-trends in the data by estimating the impact of ITES center introduction in future years $5^{5}$ The inclusion of the future ITES center measure does not affect our estimate of the impact of current ITES centers and, more importantly, future ITES centers are never a significant predictor of school enrollment. As a further test, we show that there are no trends in enrollment in years leading up to an ITES center introduction.

Following our estimates of the overall impacts of ITES centers, we turn to estimating whether these impacts vary by language of instruction. The vast majority of jobs in ITES centers require knowledge of English in addition to high rates of education. This suggests that ITES center introduction should be particularly important in impacting English-language schooling; again, the existing literature already points to increases in English-language schooling in response to the broad trends in IT. Using data on language of instruction, we find that English-language school enrollment increases by about $13 \%$ with the introduction of each ITES center, whereas there is no change (either increase or decrease) for local-language schools.

We can take this a step further and use the variation we observe in ITES center type. We argue that the impact for English-language schools should be particularly strong when the ITES center that is introduced is a voice center (as opposed to data processing), since these centers typically require a better command of English. This is apparent in the data. The impact of a voice ITES center on an English-language school is 16.4\%; this is in comparison to $-3.6 \%$ for a voice ITES center and a local language school. The difference for non-voice centers is much smaller: $12.4 \%$ for English-language schools versus $9.1 \%$ for local-language schools.

These results point to a causal impact of ITES centers on school enrollment; one important question is whether the impacts are driven by mechanical changes resulting from ITES center introductions. We evaluate three possibilities: changes in number of schools 6 , changes in population and changes in income. We argue (in Section 4.3) that these factors do not explain our results. First, there is no change in number of schools after ITES center introduction. Second, ITES center employees are typically young, without children and do not migrate for the job, suggesting ITES

ITES center operators suggested they choose where to locate primarily based on the level of infrastructure and the quality of possible employees. Nothing was mentioned about locating based on trends.

${ }^{5}$ This methodology has been used elsewhere to test for similar concerns (Jensen and Oster, 2009; La Ferrara et al, 2009).

${ }^{6}$ The particular concern in this case is that, since we observe total enrollment at each school, if schools close when ITES centers are introduced, total enrollment could remain constant while children per school increased. 
centers will not increase the population of school-aged children 7 Third, although ITES centers do increase income, a simple calibration using estimates of the income elasticity of school enrollment suggests that only a small fraction of our enrollment increases could be explained by income changes.

We interpret our results as reflecting changes in returns to schooling. In Section 5 we briefly discuss the more specific mechanism by which this occurs. In particular, we distinguish two possibilities. First, ITES center introduction may impact perceived returns to schooling by providing better information about these jobs. Alternatively, an ITES center introduction may impact actual returns to schooling if people envision working at that particular center. We present a very simple framework for thinking about this distinction, and argue that the plausibility of the latter explanation depends on the cost of travel or migration between areas. The effects we observe are very localized; these are only consistent with the actual returns explanation if migration and travel for work are extremely limited. We argue based on other data from India this does not appear to be the case. Although this evidence is only suggestive, we argue it is more consistent with ITES center introduction changing perceived returns, perhaps by increasing the salience of this type of employment opportunity. To the extent that this is the case, our results are supportive of policy interventions of the type evaluated in Jensen (2009) in which people are informed directly about returns to schooling.

The findings in this paper relate to a large literature on what policies are effective in increasing school enrollment in the developing world (e.g. Duflo, 2001; Kremer, 2003; Chaudhury et al, 2005; Duflo, Hanna and Ryan, 2009; Burde and Linden, 2009). We are most closely related to Jensen (2010), who evaluates a randomized intervention which provided call center recruiting services in the area around Delhi. He finds increases in school enrollment among girls as a result of these interventions, as well as increases in girls' weight. Relative to this paper, our work provides a clearer picture of changes which are likely to result without any formal intervention; we also have richer data on schooling (in particular, on language of instruction). However, that without randomization our study relies on stronger identification assumptions.

The rest of the paper is organized as follows. Section 2 provides some background on ITES centers, and describes our education data and our ITES center data. Section 3 describes our

\footnotetext{
${ }^{7}$ We make this more explicit using a simple calibration in Section 4.3. In addition, we also show evidence from other data that migration overall is too limited to explain our effects. In addition, in an Appendix Table we show that, in the subset of places we can control for population, including this control does not impact the results.
} 
empirical strategy. Section 4 shows the central results of the paper, discusses robustness to pre-trends and presents our results broken down by language of instruction. This section also analyzes whether the results are driven by mechanical changes in number of schools, population or income. Section 5 discusses mechanisms and Section 7 concludes.

\section{Background and Data}

\subsection{Background on ITES Centers}

Although the concept of "outsourcing" business processes to low-wage countries has been around since the 1970s, the industry remained small until the late 1990s, as time and cost restrictions were large. With the investment in trans-oceanic fiber-optic cables however, the costs of ITES off-shoring plummeted, and with its highly educated English-speaking low-wage population, India emerged as the dominant provider of business services ranging from call centers to software development. Only about 5,000 workers worldwide were employed in this sector in 1986; by 2010, this number had increased to 2.3 million in India alone (NASSCOM, 2010).

ITES center jobs are typically high-paying by Indian standards. The average starting salary at such firms is in the range of 8,000 rupees per month (about $\$ 175$ ), which is almost double the average per capita income of India ( $\mathrm{Ng}$ and Mitter, 2005). These firms typically come in two types: multinational corporations with subsidiaries or divisions located in India, and Indian "third-party" firms that provide ITES centers and other services for Western companies. Jobs at the Indian firms tend to have lower wages, higher turnover, and less training than the "in-house" multinational corporation positions (Dossani and Kenney, 2004). The majority of ITES firms are in larger cities such as Bangalore, Delhi, and Mumbai, but they are spreading rapidly to smaller cities all over southern India. Workers at these firms are primarily young, and a large share are women (Ng and Mitter, 2005).

Many of these firms are call centers, which focus on direct telephone interaction with Western customers. Workers make outgoing calls (for services like telemarketing), and take incoming calls (for customer service, tech support, and credit card activation, among other things) for large Western companies. At these centers, "voice" workers conduct calls almost entirely in English, primarily to the United States, thus fluency is generally a requirement for entry-level positions 8

\footnotetext{
${ }^{8}$ Indeed, many of these firms go to great lengths to train their workers to speak with American and British regional dialects, even adopting pseudonyms and memorizing idioms. Some workers report having to watch hours of American
} 
"non-voice" business processes outsourced to such firms range greatly in their skill-level, from data entry to software design. English proficiency may not be required for these jobs, although in our survey, almost all non-voice centers reported that English was required.

From the perspective of this paper, there are at least two central features of ITES centers which we want to highlight. First, they require relatively high rates of education and pay high wages. In both existing literature and in research done for this paper, it is clear that the vast majority of these jobs require at least a high school degree, and in many cases more. To the extent that jobs of this type have not been available historically, their existence may well affect the returns to education (both perceived and actual). Second, the vast majority of these jobs require English skills, which is likely to affect the wage returns to learning English.

\subsection{Data on School Enrollment (DISE)}

We use a large administrative dataset on primary school enrollment in India called the District Information System for Education (DISE). This dataset has been collected by the Indian government since the late 1990s, although the data used in this paper begins in the early 2000s. Data collection is coordinated at the district level, and involves surveys of schools. These school surveys have several parts. First, they collect data on primary school enrollment, including comprehensive data on number of enrolled students by age, grade, gender and caste. These data are designed to reflect statistics as of September 30th of the school year (which starts in the spring). Second, they collect data on features of the school, including language of instruction and physical plant characteristics. Each school, and each village, is given a unique ID number which allows us to follow schools over time 9

The village-level survey is less comprehensive and less frequent, but includes some information on village characteristics. Most importantly, in the village-level survey we observe (for most villages) the PIN code location of the village, which will allow us to match to ITES center locations. A PIN code is similar to a ZIP code in the US; they are larger than a village, but not as large as a census block. In these data, the median PIN code has 10,000 children enrolled in primary school.

television programs to help perfect their speech patterns. (Ng and Mitter, 2005)

${ }^{9}$ In cities, a "village" is really a neighborhood, or ward. For example, in Bangalore, a city with 6.5 million people in the 2001 census, there are 668 distinct "villages". 
The DISE data is collected by the district, and then aggregated by each state government. We use data from three states which have been significantly impacted by globalization: Karnataka, Andra Pradesh and Tamil Nadu ${ }^{10}$ The number of years of data varies across states. Panel A of Table 1 shows, for each state, the years of data coverage and the range of number of schools by year. In later years the dataset is more comprehensive, covering a larger share of schools. Although this means we do not have a balanced panel, by including school fixed effects we ensure we are comparing the same schools over time.

Panel B of Table 1 provides some summary statistics on school enrollment and school characteristics. The average school in our sample is fairly small, with 144 students. Younger grades are larger on average, consistent with some drop out over time, and there are roughly similar numbers of girls and boys. This survey covers only primary schools, so we observe enrollment only up to eighth grade. The physical plant variables indicate schools are not in very good repair. In an average school, only $70 \%$ of classrooms are noted to be in good condition by surveyors. Half of the schools report having a boundary wall, half report having electricity and slightly above half have a toilet. When we turn to mechanism we will explore variation based on whether or not the school teaches in English; 11\% of the sample reports at least some instruction in English.

This data has several limitations. First, although it aims to be a complete census of schools in India, the coverage sample differs somewhat across years, indicating that some schools are missed in some years and it seems likely that others are missed completely. Because we run our regressions at the school level, with school fixed effects, we argue that this is not an issue for interpreting our estimates. The one note of caution, however, is that if the schools we observe are different than the schools we do not observe, our results may have limited generalizablity; this is unlikely to be a significant issue, however, since our best estimates suggest we cover nearly all schools in India.111

A second issue is that the data collects information on total number of children enrolled, not enrollment rates. Given the evidence reported in the introduction, and in Section 4.3, that ITES centers are unlikely to have any noticeable impact on the population of children, this is should not be

\footnotetext{
${ }^{10}$ These three are also states in which we have a relatively long time series of data; although we have access to data for the entire country, in most states they cover only two to three years.

${ }^{11}$ This is actually a somewhat difficult fact to measure. Official statistics on number of schools in India appear to be largely based on the same data we use here so there is no outside source that we can use to verify coverage. The fact that the Indian government uses this as the source of official statistics, however, gives us confidence that we are covering at least an extremely large share of total schools.
} 
a major issue. However, for a small subset of school years the school also reported the total population of school-aged children in the area. The coverage of these data are limited, and it is unclear how the schools estimated total population. Nevertheless, in a robustness check we will use these data and the variable is summarized in Panel B of Table 1 .

Finally, as noted, the DISE data covers only primary schools. It seems plausible, even likely, that much of the impact of ITES centers would be on enrollment in high school, since secondary school education is typically necessary for these jobs. Unfortunately, we do not observe these enrollments; if anything, this may lead us to understate our impacts since we may not observe the highest-impact age groups.

\subsection{Data on ITES Centers}

To match with the data on education, we collected a dataset of ITES center locations in the same three states. We contracted with a firm in India that helps connect Western firms with Indian ITES centers to create a directory of ITES centers in Andhra Pradesh, Karnataka, and Tamil Nadu. They used their contacts, the Internet, and available directories to compile a list of firms, and called each to confirm their existence, the PIN code of their location and founding date.

This data collection project resulted in a dataset of 385 ITES centers. Figure 1 shows a histogram of ITES center founding dates; the incredible growth in number of centers over time is clear: in our sample, $68 \%$ are founded after the year 2000. As we noted above, our data on schooling is collected in September, for the year spanning June to April and the ITES center founding dates are given a simply the calendar year of founding. To match, we code the school year 2005-2006 as 2005, and match with ITES centers this way. So a school in a PIN code with an ITES center introduced in 2005 is coded as having a new ITES center in the 2005-2006 school year 12

The breakdown of number of ITES centers by state is presented in Panel A of Table 2, In Column 1 we show the count of all ITES centers; Andra Pradesh is slightly less well-represented, but the number of ITES centers is fairly similar across states. In Column 2 we report these counts for areas outside the major cities of Bangalore, Chennai and Hyderabad (this is the sample we use for analysis). As expected, this limits the sample considerably, since most ITES centers are in major

\footnotetext{
${ }^{12}$ We collected only year of founding date for the ITES centers, not month, which means we are not able to do a more sophisticated matching with date of entry.
} 
cities. However, we are still left with 244 ITES centers. We choose this sample restriction because, given the large number of ITES centers in these cities, it is difficult to think of the introduction of one more as an event.

In order to undertake our analysis, we aggregate these ITES centers to the PIN code level. The first column in Panel B of Table 2 reports data on number of ITES centers by PIN code. The vast majority $(97 \%)$ of PIN codes do not have any ITES centers; among those with at least one ITES center, the average is 2.6. Column 2 in Panel B shows these statistics with the data restricted to the sample we use (areas outside of the three major cities). This sample is similar, and the conditional average is 2.5 ITES centers.

Panel $\mathrm{C}$ of Table 2 gives a better sense of the source of identification we use by showing three categories of schools. Our sample contains roughly 238,000 schools which are in PIN codes which never have ITES centers (or at least not ITES centers we observe). A further 172 schools are in PIN codes which have ITES centers, but do not change their ITES centers during the survey period. Finally, we have 408 schools in PIN codes where the number of ITES centers change over the course of the study. Given that our specifications will include school fixed effects, we are identifying off of these final 408 schools. In general, we will include all schools in our analyses, and the non-changers will serve to identify the basic trends over time; in some analyses will we include only schools which ever have an ITES centers (a total sample of 580 schools) ${ }^{13}$

In addition to this basic information on ITES center locations and founding dates, we undertook a follow-up survey of the centers in our sample to get a sense of characteristics. Although we attempted to survey all centers, in the end we were able to collect data on $83 \%$ (the remaining were missed largely due to refusal to answer survey questions). For these centers we have data on whether or not they are voice centers, whether they operate in English, the number of employees and several employee characteristics. Information on number of employees and whether they are voice or non-voice is available for all the centers we surveyed; demographic information is available for a smaller subset.

The variables are summarized in Panel D of Table 2. The ITES centers are relatively small, with a median of 80 employees, and about half of them have voice operations. All ITES centers

\footnotetext{
${ }^{13}$ One issue we should highlight here is that most of the changes in our sample take place between 2005 and 2006 ; this does not seem to reflect the distribution in timing of ITES center introduction, but rather the fact that the meat of our schooling data is in this period.
} 
which handle voice calls operate at least in part in English. Employees are young (median age of 28), largely without children and largely from the local area.

As a final note, in addition to ITES centers within the same PIN code as the school, we use two variables measuring slightly further centers: those in the two closest PIN codes, and those in the 3rd to 5th most distant PIN codes. To calculate distance, we use GIS data on PIN code locations (the latitude and longitude are measured at the post office in each PIN code). We calculate the distance from each PIN code in the data to all other PIN codes, and rank them by distance to define the closest ones. We then calculate the number of ITES centers in each of these two neighboring groups. The two closest neighboring PIN codes are an average of 2.3 miles away, and 1,117 schools ever have an ITES center in one of these closest neighbors; the further neighbors are an average of 4.6 miles away and 1,935 schools ever have an ITES center in one of these areas.

\subsection{Placement of ITES Centers}

A central issue in our analysis is the fact that ITES centers are not placed randomly. Our analysis will take advantage of variation over time, so any fixed differences across areas will be adjusted for, but it remains important to understand what drives placement.

We undertake two strategies. First, we can get an initial sense of the magnitude of this threat based on discussion with ITES center operators about location choices. The primary issues they cited when deciding where to locate were infrastructure and transportation: areas with no electricity and roads were not appealing places to operate. In addition, center operators cited their need to get high quality employees cheaply in the local area (this is consistent with the survey data which suggests limited migration for work). There was some sense of a trade-off: there are more qualified individuals in larger cities, but people in more isolated areas (smaller cities, towns) demand lower wages. These discussions certainly do not suggest that ITES centers are placed randomly; it is clear that center operators are thinking carefully about cost-benefit considerations. However, the central issues raised are very likely to be constant over time, at least over the short time frame of our study.

We are also able to evaluate this endogenous placement statistically using our data. To do this we estimate, at the village level, (a) the determinants of having an ITES center by the end of the sample in 2007 and (b) the determinants of adding an ITES center during the period we observe. We 
focus on variables cited by ITES center operators: whether the area has electricity, whether it is in a more urban area and whether there is an English-language school in the area. This last variable is intended to capture the availability of English-speaking individuals. We also include a control for total school enrollment and, in some cases, state fixed effects.

The results from these regressions are shown in Table 3. In general, our evidence is supportive of the interview evidence. More urban areas are more likely to have centers by 2007 and more likely to add them during the sample; these impacts are true with and without state controls. Areas with English-language schools are also more likely to have centers and more likely to add them during the sample; again, this results is robust to state fixed effects. We see limited evidence that electricity matters, although this may be due to the high correlation with urbanization; enrollment also does not seem to have any impact.

The inclusion of school fixed effects means that any differences in levels of enrollment associated with these variables will not impact our results. However, if there are differential trends in enrollment across villages associated with these variables, this could impact our results. To address this, in the results below we will allow for differential year fixed effects for areas that are more urbanized and areas with any English-language schools; this is discussed in more detail in Section $3{ }^{14}$

\section{Empirical Strategy}

We estimate the impact of ITES centers on school enrollment using a fixed effects estimator. We observe enrollment (total number of children enrolled) in school $i$ in PIN code $j$ at time $t$; denote this variable $n_{i j t}$. In addition, we observe number of ITES centers in PIN code $j$ at time $t$, which we denote $c_{j t}$. Our basic regression is shown in Equation (1) below

$$
n_{i j t}=\alpha+\beta_{1} c_{j t}+\gamma_{i}+\phi_{t}+\mathbf{\Psi} \mathbf{X}_{\mathbf{i j t}}+\epsilon_{i j t}
$$

where $\gamma_{i}$ is a vector of school fixed effects, and $\phi_{t}$ is a vector of date controls. These date controls include year fixed effects, and year fixed effects interacted with state fixed effects, village-level electricity, urbanization and controls for the number of English-language schools. Put differently, we

\footnotetext{
${ }^{14}$ We do not include separate trends in electricity or initial enrollment level since these do not impact placement; consistent with this lack of impact on placement, including these does not change our results.
} 
allow the year fixed effects to differ by state and by the variables which drive ITES center placement in Table 3. In addition to these fixed effects, we include a set of school-specific time-varying controls $\left(X_{i j t}\right)$ measuring school-level infrastructure. The coefficient of interest is $\beta_{1}$, which captures the effect of ITES centers on school enrollment, identified off of schools in areas which add ITES centers during the sample. Throughout the analysis, we cluster our standard errors at the village level[15 We will also estimate several variations on this regression, including limiting to areas which are more likely to have centers, estimating the impact of having any centers and controlling for district-specific time trends.

As noted in the introduction, we are concerned in this analysis about the possibility that the results are driven by other variables which are changing over time and influence both ITES centers and school enrollment. A related issue is the possibility that ITES centers are introduced in places where school enrollment is increasing. To address both of these issues, we explore whether future ITES centers predict current enrollment. To do this, we estimate Equation (2) below.

$$
n_{i j t}=\alpha+\beta_{1} c_{j t}+\beta_{2} c_{j, t+1}+\gamma_{i}+\phi_{t}+\mathbf{\Psi} \mathbf{X}_{\mathbf{i j t}}+\epsilon_{i j t}
$$

where $c_{j, t+1}$ is a variable measuring number of ITES centers in PIN code $j$ in the next year. We argue that a finding that $\beta_{2}=0$ implies no pre-trends: that is, enrollment is not higher in areas that get ITES centers in the future. It is important to note that this technique does not allow us to rule out the possibility that ITES centers are introduced at exactly the same time as another innovation, and that other innovation drives school enrollment. However, this possibility seems much less plausible than the general trend story.

As a secondary pre-trend analysis, we also estimate Equation (2) including a trend for years until a new ITES center is introduced. This allows us to look slightly more generally at whether enrollments are increasing in years up to a new ITES center introduction.

One important issue is the coverage of our ITES center dataset. Although we worked to cover as many ITES centers as possible, it seems extremely unlikely that coverage is perfect. There are

\footnotetext{
${ }^{15}$ We choose to cluster at the village level (rather than the school) since $c_{j t}$ is the same for all schools within a villageyear. In fact, the level of clustering makes relatively little difference - even clustering at the district level gives very similar standard errors. We should note that when we include district-specific trends in the regression (see discussion below) we are not able to cluster at all given the large number of controls (STATA refuses to calculate standard errors). This means the standard errors are likely biased downward in those regressions, although since the clustering does not make a large difference in general, it seems unlikely they are biased downwards very much.
} 
very likely areas that have ITES centers which we do not observe. This means that our "control" group of non-changers also contains some schools which should be in the "treatment" group. To the extent that there is a positive effect of ITES centers on school enrollment, this imperfect coverage should bias our estimates of $\beta_{1}$ downward, since the changes in the control group will be more biased upward by the inclusion of "treatment" schools.

\section{Results: Impact of ITES Centers on School Enrollment}

This section presents our estimates of the impact of ITES centers on enrollment. In the first subsection we summarize our basic results, report variations in the effect by demographic group and address the concern that the results we find are driven by pre-trends. The second subsection presents our results broken down by school language. The third subsection discusses whether our results are driven by mechanical changes in population or income.

\subsection{Baseline Results, Pretrends}

We begin by showing the central result in the paper in graphical form, in Figure 2. To generate this figure, we focus on four groups of schools: schools which always have an ITES center in their PIN code, schools which add a center between 2004 and 2005, schools which add a center between 2005 and 2006 and schools which never have any ITES centers ${ }^{16}$ For all four groups we isolate on a balanced panel of schools which are observed for four years (2004-2007). Using this sample of schools, we regress log enrollment on year fixed effects and take the residuals; this removes any consistent year-by-year variation. These residuals are graphed in Figure 2, which show changes in these residuals relative to the level in 2004.

The key result in Figure 2 is that there are large year-on-year changes in enrollment in the two groups which add ITES centers during the sample, and these changes line up in terms of timing with the ITES center addition. In areas which add a center between 2004 and 2005, schools see a large increase in enrollment between these years, whereas there is only a small increase in schools which

\footnotetext{
${ }^{16}$ The two groups of changer schools here (add center in 2005 and add center in 2006) cover the vast majority of schools which add centers; this is due largely to the meat of our schooling data being from this period.
} 
always have centers, and no change for schools which add centers later or never add them ${ }^{17}$ Further, for areas which add an ITES center between 2005 and 2006 there is a large increase in enrollment between these years, but no change in the year before; further, this is the only group with a large increase between 2005 and 2006. Overall, the figure demonstrates large changes in enrollment for areas which add ITES centers during our sample and these changes line up in terms of timing with ITES center introduction.

Panel A of Table 4 shows our statistical estimates of the effect of ITES centers on enrollment. Column 1 presents our primary specification using the entire sample and controlling for school fixed effects, time-varying school infrastructure variables, year fixed effects and these year fixed effects interacted with several important determinants of ITES centers. The coefficient on ITES centers is positive and significant: adding one more ITES center appears to increase school enrollment by $5.7 \%$. Columns 2-4 of Panel A present several modifications on this regression. In Column 2 we include controls for district-specific trends, to address the concern that districts which have ITES centers introduces are trending differently than those that do not. The coefficient is slightly smaller $(4.3 \%)$ but within the margin of error of the estimate in Column 1. In Columns 3 and 4 we restrict the sample to areas which are arguably more comparable to the areas which get ITES centers; this addresses the concern that it is inappropriate to use areas which are very unlikely to get ITES centers as the comparison group. Column 3 limits to villages with at least one English-language school and Column 4 limits to areas which ever have an ITES center which we observe (including those which change and those which always have a center). In both of these restricted samples, the effect is actually larger and more significant. Perhaps most striking is the evidence in Column 4, which contains our most comparable set of schools: even though the sample size is extremely restricted in this case, the effects are still large and significant.

In Panel B of Table 4, we estimate the same regressions, but instead of estimating the impact of number of ITES centers, we focus on a dummy for whether the area has any centers. The impacts are of similar size but less precise in this case; the p-value on the overall sample is 0.11 . The lower precision may be due to having more limited scope for identification once we throw away some of the changes. We should note this does suggest that the results we observe do not arise only from the first

\footnotetext{
${ }^{17}$ As shown in Table 2 most schools never have any ITES centers. For this reason, the year fixed effects are largely identified off of these areas, so when we generate residuals removing these fixed effects, the average residuals in these area are very close to zero.
} 


\section{ITES center introduction.}

The results in Panels A and B focus on the impact of ITES center introduction into the very local area - PIN codes in the same village as the school. In Panel $\mathrm{C}$ of Table 4 we explore whether the introduction of ITES centers in the slightly broader surroundings matter. As described, we do this by estimating the impact of ITES centers in the two closest neighboring PIN codes, and slightly further neighbors (the 3rd to 5th closest). Panel $\mathrm{C}$ demonstrates that there are some impacts for ITES centers in the nearest neighbors: one more ITES center in one of the closest neighboring PIN codes results in a $3.6 \%$ increase in enrollment in the primary specification. However, this impact is typically slightly smaller than the own-PIN code centers. Further, the effects fall off very quickly. ITES centers in the slightly more distant neighbors have no impact; this is true even though these "distant" neighbors are still quite close, at an average of 4.6 miles away. This suggests effects are extremely localized.

The evidence in Table 4 suggests a strong connection between ITES centers and total number of children in school. In Appendix Table 1 we show these effects broken down by demographic group and state. We find the effects are similar for girls and boys and larger for older than younger children. The effects are similar for each state, although not significant in Andra Pradesh or Karnataka, likely due to the more limited sample.

\section{Pretrends}

The central threat to the validity of our estimates is that pre-trends in enrollment or other variables drive our results. This is related to the issue of endogenous ITES center placement, which is clearly a concern, as can be seen in Table 3. As discussed above, to the extent that endogenous placement reflects only characteristics which are constant over time this will not drive our results due to the inclusion of school fixed effects. Further, if trends are different for areas which are urban, or have more English-language school, we have also addressed this concern. The concern which remains unaddressed in our main specification is the possibility that ITES centers are located in areas that are changing more quickly in other ways that we do not observe. We note that, anecdotally, nothing in discussions with center operators suggest this is the case.

To address this concern directly we estimate whether future ITES center placement predicts 
current enrollment. If ITES centers are being placed in areas in which other variables are changing, or in which enrollment is increasing in general, then we expect to observe future ITES center placement affecting current enrollment. This test is similar or identical to the tests for pre-trends in other comparable settings (Jensen and Oster, 2009; LaFerrara et al, 2009).

Panel A of Table 5 replicates Panel A of Table 4, but includes a control for the number of ITES centers in the following year in addition to the indicator for current ITES centers. Adding the control for future ITES centers has only a small impact on our estimates of the effect of current ITES centers. In addition, and more importantly, the effect of future ITES centers is small and not statistically precise, suggesting no strong evidence of pre-trends. We should note, however, that the estimates are too noisy to reject equality between the coefficients.

In Panel B of Table 5 we do a similar test, but rather than simply controlling for having an ITES center next year, we control for a time trend up to the year of ITES center introduction (the trend is defined so higher values indicate the center introduction is closer in time). If ITES centers are introduced into places where enrollment is increasing more quickly, we should see evidence of a positive trend. We do not see this. In Column 1, the coefficient on the trend is 0.002 , indicating a $0.2 \%$ increase in enrollment for each year closer to the introduction of the ITES center. This is not significant, and is tiny relative to the $6.1 \%$ impact of introducing the ITES center. The trend is similarly insignificant and small in other columns. It is important to note that the results here do not indicate that ITES center placement is exogenous - this is effectively ruled out by the evidence in Table 3 - but instead indicate that this endogenous placement does not drive our results.

\subsection{Impacts of ITES Centers by Language of Instruction}

The evidence above suggests that overall school enrollment increases in response to ITES center introduction. Here, we turn to separating the result by language of instruction. One of the most central features of ITES centers in India is that the vast majority operate in English. In our survey, all of the voice ITES centers (which make up about half of our sample) use English; the majority of non-voice centers also require English. Given this, to the extent that what we observe reflects changes in schooling in response to job opportunities, these changes should disproportionally result in higher English-language school enrollment. Broadly, we see strong evidence of this in the data 
presented by Munshi and Rosenzweig (2006). They show increases in the returns to English-language education in Bombay over time, and subsequent increases in English-language schooling. Again, we explore largely the same issue here, but are able to identify responses of English-language schooling to local job opportunity changes.

We test for differences across language of instruction in Table 6. To do this, we generate new variables interacting the number of ITES centers with language of instruction. We control separately for the impact of ITES centers on local language schools, and on English-language schools 18

Panel A of Table 6 shows our basic test of differences across school types. Column 1 reports impacts on total enrollment using the entire sample. We find the total impact of ITES centers in English-language schools is large and significant; the impact of ITES centers in local-language schools is effectively zero. Enrollment in English-language schools increases by $14.9 \%$ for each ITES center introduced. The p-values reported at the bottom of the table indicate we can strongly reject the equality of the impacts in the two school types. In Columns 2-4 we estimate this regressions with district-specific trends (Column 2) and in the two restricted samples (Columns 3 and 4). In all cases we see the same pattern of strong impacts on English-language schools and none for local-language. One thing which is important to note is that we do not see decreases in enrollment in local language schools. The increase in enrollment in English-language schools does not appear to come at the expense of enrollment in local-language schools.

In Panel B of Table 6 we push the data on language further, and separate schools into three groups: those which do not teach in English at all, those which teach some in English and some in another local language and those which teach only in English. We replicate Panel A, but control for each school type interacted with ITES centers. Consistent with the larger impact for English-language schools overall, we find the effects are largest for schools which teach exclusively in English. However, the difference between these and those which teach partially in English are fairly small. The largest distinction appears to be between schools which teach at least some English and those which teach none.

We can further explore whether the enrollment changes seem to reflect response to the ITES center jobs by using the distinction between voice and non-voice ITES centers in our sample. As noted in Section 2, our sample of ITES centers includes both centers which engage in voice activities

\footnotetext{
${ }^{18}$ The two variables are mutually exclusive; each coefficient can be interpreted as the effect for that school type.
} 
(true "call centers") and those which engage in non-voice activities (data processing, software development, etc). Speaking English well is particularly valuable for jobs in voice centers. Although most non-voice centers also require English, they are slightly less likely to do so and the necessary level of English proficiency is clearly lower. We evaluate the impact of voice centers over and above the impact of total centers.

We generate new variables measuring the number of voice and non-voice ITES centers in each PIN code; we define a center as a "voice center" if at least $50 \%$ of employees handle voice calls ${ }^{19}$ We interact each of these new variables with school language. Our goal in this regression is to test whether the differences between English-language and non-English-language schools are larger for voice than non-voice centers. These regressions are reported in Panel $\mathrm{C}$ of Table 6. In all four columns, the coefficients tell a similar story. For non-voice centers, the effects for English-language schools are slightly larger, but the difference is small. Both types of schools see enrollment increases from non-voice centers. For voice centers, however, the impact for English-language schools is much larger than for local-language schools. We can typically reject that the difference between English-language and local language schools is the same for voice and non-voice center introductions. Interestingly, in some specifications we see evidence of a reduction in enrollment in local-language schools when a voice ITES center is introduced; this could reflect students substituting between school types, which is not an effect we observe when we consider the impact of all ITES centers combined.

Before moving to robustness, it seems worthwhile to briefly discuss the magnitude of these results. The evidence in Table 6 points to a roughly $14.9 \%$ increase in number of students enrolled in response to an ITES center introduction. The median English-language school in an area with at least one ITES center has 158 students, implying an increase of about 23 students per school after an ITES center introduction. Aggregating to the PIN code level, we estimate the total increase in enrollment (which is entirely in English-language schools) of 400 students for each ITES center introduction.

\footnotetext{
${ }^{19}$ As noted, we have voice/non-voice data for $83 \%$ of ITES centers. For the centers with data, we generate indicator for whether they are voice centers or non-voice centers. For the purpose of this analysis only, we do not include areas which have centers but for which we do not observe whether they are voice or non-voice. The results are similar if we assume they are one or the other.
} 


\subsection{Robustness: Number of Schools, Population and Income Changes}

This subsection addresses several key robustness issues. In particular, we evaluate whether it is possible that our results are simply driven by mechanical changes in number of schools, population or income deriving from the ITES center introduction. Evaluating these mechanical issues is important before we move to discuss the returns-to-schooling mechanism in Section 5.

Changes in Number of Schools A key downside of our data on education is that we observe number of students enrolled, not enrollment rates. This introduces at least two possible mechanical drivers of our results. The first concern is that our results are driven by changes in the number of schools in the area. If the introduction of an ITES center causes a decrease in the number of schools then the remaining schools could see enrollment increases even if the total enrollment rate in the area remains constant.

We can evaluate this by estimating the impact of ITES center introduction on the count of schools in the village. We collapse the data to the village level and generate a new variable which is the log number of schools in the village. We use this in regression of our standard form, and the results are shown in Table 7 . The results indicate that changes in school count is not a concern: the impact on number of schools is very small, and not significant.

ITES Center Driven Population Increases A second related issue is the possibility that population might increase in response to the ITES center. The controls thus far rule out the possibility that our impacts are driven by ITES centers being introduced to more populous areas, or ares which are growing faster. However, if the ITES center itself increases population, this could produce our result. This would be a concern if we were, for example, considering the impact of introducing a large manufacturing plant to an isolated area. However, we argue it is unlikely to be a concern in this setting.

The main reason to reject this mechanism is that ITES centers tend to employ young, childless individuals. This can be seen in anthropological and ethnographic work on ITES centers in India (i.e. Ng and Mitter, 2005) and directly in our ITES center survey data. In the average center in our sample, managers reported fewer than $10 \%$ of employees had children (see Table 2), so the potential increase in children in the area even if all employees were new to the area is small. Further, relocation for work in ITES centers is also relatively rare (11.6\% of employees). Even if we assume all this relocation is by people with children we find an average of $5.6 \%$ employees with children 
relocate; at the median ITES center, this amounts to 4 people with re-located children 20 In fact, this number is likely to be an upper bound; in reality, the individuals with children will generally be the least likely to relocate. We argue that this institutional setting effectively rules out the possibility that ITES-center driven population increases drive our effects.

There remains a lingering concern that the introduction of an ITES center may bring with it other businesses, which could increase population. One issue is that businesses which serve ITES center workers could enter at the same time. Although this is plausible, it seems unlikely the effects would be large since the number of employees is very small compared to the overall population.

It is also possible that the introduction of an ITES center is associated with an overall increase in other types of businesses, which bring in more migrants. The fact that we can reject pre-trends in the regressions above limits this concern; for this to drive our results, it must be the case that these other businesses enter at exactly the same time. In addition, we provide two other pieces of data to address this.

First, in Appendix Table 2 we show, for the subset of areas for which the school reports total area (town, village) population, the impact of controlling for population on our results. ${ }^{21}$ We do not want to lean very heavily on the evidence in these regressions since (a) we observe population only for a small subset of the sample and (b) it is unclear how the school estimated population. However, this table demonstrates that including a control for population in the regressions does not significantly impact the estimate of the effect of ITES centers. The coefficients are noisier, but this seems to be due to changes in sample: there is very little difference between Panel A (where we use the restricted sample but do not control for population) and Panel B (where we do control for population).

Second, in other household survey data (the 1998 and 2005 National Family and Health Survey) we can estimate what share of school-age children report migrating to a new area within the last year. For $88 \%$ of clusters in the NFHS sample there are zero in-migrants in the last year among school-aged children ${ }^{22}$ Even the clusters at the 90 th percentile on this measure still have only $3.5 \%$

\footnotetext{
${ }^{20}$ This is generated by taking the minimum (for each center) of the share relocating and the share with children; this number is the maximum possible share of people who have children and relocated. If individuals who relocate are mostly those without children, as seems likely, this is an overstatement.

${ }^{21}$ Since there are multiple schools in each area, we cannot generate enrollment rates off of these data, since the population reported is an area-level population not simply the population relevant for that school. The fact that this is true should also be clear from the coefficient on population; it is much lower than one, which at least partially reflects the fact that as the area population increases, not all of that increase goes to a given school.

${ }^{22}$ In the NFHS a survey cluster typically covers a single village or area within a town and includes a randomly selected subsample of individuals.
} 
of school-aged children who have migrated in in the last year. Put simply, there is very limited total migration. This further bolsters the argument that population changes are unlikely to drive our results.

ITES Center Driven Changes in Income A final possibility, also somewhat mechanical, is that ITES centers drive enrollment because they increase income and schooling is a normal good. Although this effect is not mechanical in the way population changes are, it is a very different explanation than the theory that the effects are driven by knowledge of the new job opportunities.

To evaluate the contribution of income, we take advantage of the fact that existing literature has provided estimates of the income elasticity of school enrollment in similar contexts. Using these estimates, alongside estimates of the increased income generated by new ITES centers, we can estimate the predicted enrollment increase resulting from income changes.

This is done in Table 8 . We begin by showing (in the top row) several estimates from existing literature of the income elasticity of school enrollment. These are taken from a studies done in a variety of developing countries, with varying methodologies (Alderman et al., 2001; Glick and Sahn, 2000; Glewwe and Jacoby, 2004; Orazem and King, 2007). In the second row, we show our estimate of the percentage increase in income generated by ITES centers; this is the same in all columns. Details of this calculation are in Appendix A. This increase is extremely small: about $0.57 \%$. Although ITES centers pay quite well, they simply do not employ a large number of people, so the income increase is quite limited.

The first and second rows together allow us to estimate the expected change in enrollment given the change in income. The predicted percent increase in enrollment ranges from $0.17 \%$ to $0.84 \%$. Our actual enrollment increase is $5.5 \%$, an order of magnitude larger; put simply, even at the largest elasticity estimates in the literature, it is unlikely that much more than a tenth of the effect is explained by income increases. Unless the relationship between ITES center income and school enrollment is somehow very different than that between regular income and school enrollment, the vast majority of the enrollment change must be driven by something other than changes in income ${ }^{23}$

\footnotetext{
${ }^{23}$ Since the increases we see in schooling are primarily driven by increases in English schooling, it is possible to argue that there is some other income elasticity for English schooling particularly, which is higher than the income elasticity than schooling more generally. This seems unlikely; the income elasticity of English schooling would have to be 25.6, or more than twenty times higher than the highest estimate for income elasticity of schooling in the literature.
} 
Similar to the case of population, an auxiliary concern is that the ITES center brings other businesses, which also increase income. It is more difficult to rule this out than in the population case, since this could occur even though population does not change. However, it is worth noting, again, that the fact that we do not see evidence of pre-trends suggests that these new businesses would need to arrive at exactly the same time as the ITES centers. In addition, given the very small share of the effect which is plausibly explained by ITES center income, in order for income overall to explain a larger share, these other businesses would need to swamp the ITES centers in their income contribution.

\section{Mechanisms: Actual Changes in Returns Versus Changes in Information}

Based on the results in Section 4, we draw several conclusions. The introduction of an ITES center to an area results in an increase in school enrollment and this increase is concentrated in English-language schools. The observed increase does not appear to be driven by mechanical changes in the number of schools, population or income. Most importantly, these changes are very localized: ITES centers even slightly further away have a limited or zero impact on enrollment. The concentration of the impacts in English-language schools, the absence of pre-trends and the rejection of mechanical impacts driving our results, lead us to argue that the effects we observe reflect responses to changes in the perceived value of education after the introduction of new local job opportunities.

In this section we provide some initial evidence on whether these changes reflect changes in actual returns to education resulting from the local job opportunities, or whether they reflect increases in information about returns to education with limited change in the actual returns. This distinction is potentially important for thinking about the policy implications of these results. If these change reflect changes in actual returns, this suggests that in the long term we expect increasing education to be limited to areas where new job opportunities arise. In contrast, if the effects reflect increasing information, then policies which inform people about job opportunities (as in Jensen, 2009) may be effective in increasing schooling. In this section we discuss this distinction and provide several pieces of evidence which, we argue, suggest that the changes in actual returns 
from such local changes are very limited. By extension, this suggests the information story is a more plausible explanation. However, we caution that this analysis is much more speculative than the central results shown above.

To fix ideas, consider the simplest model of schooling decision-making in this context with no information asymmetries. Assume there are two locations, A and B, both of which begin with no ITES centers and otherwise identical job opportunities. Assume education is a binary choice, with wage returns $W_{E}$ representing the increased lifetime wages from becoming educated, and assume costs of education are the same in both areas. At some date, an ITES center is introduced into area A and (because we are assuming there are no information asymmetries) it is immediately observable to individuals in both areas. The existence of this center increases the wage returns to education to $\hat{W}_{E}>W_{E}$ while education costs remain the same.

For individuals in area $\mathrm{A}$, the value of education increases by $\hat{W}_{E}-W_{E}$, the full difference in educated wages before and after the new job opportunities. For individuals in area B, however, the increase is less because to take advantage of the new jobs, they would need to migrate to area A; denote the cost of migration $C_{M}$. For these individuals, the increase in the value of education is $\hat{W}_{E}-W_{E}-C_{M}$. Assuming that $C_{M}$ is positive, we expect the reaction of individuals in area B to be smaller than area A; how much smaller depends on the size of $C_{M}$.

If the relevant costs of migration are very large in our context, then it is plausible that the impacts we observe reflect changes in actual returns prompted by ITES center introduction. In contrast, if migration costs seem to be small over the relevant distances, then this is less plausible. The obvious alternative is a model with information asymmetries which could explain differences in response with no difference in $C_{M}$ by simply positing that the perceived increase in returns is lower in the non-local area due to lack of information.

The effects we observe in the data are very localized; given this, the relevant costs of migration are between very local areas. Recall that we argue in Section 4 that the impact of ITES centers falls to zero when we look at those introduced in PIN codes even a few kilometers away. This is consistent with the actual-returns story only if migration is limited over even this very small distance. We argue this is unlikely.

First, based on data from a household surveys (the National Family and Health Survey), we find that migration among young, high-education individuals (i.e. those who might work in ITES 
centers) is actually quite common. Among working men aged 20-35 with at least a secondary school education, $30.3 \%$ have moved in the last five years. For women (again, limiting to those working, aged 20-35 and with a secondary school education), this figure is $25.7 \%$. Although we cannot observe how far they moved, or whether they moved for work, this does suggest it is not unrealistic to expect migration for work as a possibility. This relatively high mobility is confirmed in the census. In the 2001 Census, $29.9 \%$ of persons were living in a town other than that of their birth, with most of these migrants remaining in the same district. For men, the most common reason for migration was work $(37.6 \%)$.

Second, given how localized the impacts are, it is not even clear that an accurate measure of $C_{M}$ should necessarily include the cost of moving to a new location. Banerjee et al. (2001) shows that the average commuter in Thane, India travels 30 minutes (on foot) to their job; this amounts to about 1.5 miles. Roughly $20 \%$ of individuals in their sample travel more than 4 miles. To the extent these figures are similar in our areas, this suggests that the impact of ITES centers falls off to zero even within reasonable commuting distances, where the cost of "migration" would only involve commuting costs.

Together, this evidence suggests that the differential change in returns to schooling for people living right in the same neighborhood as the new ITES center and those living a few miles away is probably not very large. Migration is fairly common, and even without moving their home, people could work a few miles away while still living in their old home. This suggests that the effects of ITES centers we observe probably do not reflect changes in actual returns to schooling and, by extension, may reflect changes in perceptions about returns to schooling.

As a final note, the perceived returns story is also more consistent with the magnitude of our results. We find a total enrollment increase of roughly 400 students for each ITES center added; weighted by schools, the median ITES center added has 200 employees. The fact that the additional enrollment outweighs the additional jobs also makes it less likely that these changes reflect responses to actual returns to schooling. It is important to be clear, however, that the conclusions in this section are necessarily much more speculative than the primary results. 


\section{Conclusion}

In this paper we argue that the introduction of ITES centers in India have large impacts on school enrollment, and these impacts are largely concentrated in the very local area around the ITES center. We argue this effect is causal, and is not driven by pre-trends or mechanical changes in number of schools, population or income. The very local nature of our analysis and the fine timing of the effects are helpful in ruling out the concern that pre-trends in other variables drive the impacts we see. Further, we provide some suggestive evidence that the very localized nature of the impacts may reflect limited information about non-local job opportunities; we argue this is more likely than the claim that these new job opportunities only impact local returns to schooling.

These results relate to a larger literature on promoting schooling increases in the developing world. To get a sense of magnitude, we can compare the results here to other interventions designed to increase schooling. Our overall estimate indicates that an additional ITES center prompts a $5.7 \%$ increase in school enrollment; based on an enrollment rate of around $80 \%$ this amounts to an increase in enrollment rate of around 4.1 percentage points. This number is comparable to enrollment effects of other interventions designed to increase schooling in the developing world. For example, the conditional cash transfers in PROGRESA increased schooling 3.4-3.6 percentage points (Schultz, 2004). A program in Kenya which provided school uniforms to girls in Kenya (worth about $1.75 \%$ of average yearly income) increased enrollment by 6 percentage points (Evans, Kremer and Ngatia, 2008). Miguel and Kremer (2004) found that administering deworming drugs decreased absence by 7 percentage points, although they do not report effects on enrollment.

From a policy standpoint, our results may provide support for interventions which inform students about returns to schooling (as in Jensen, 2009). In the absence of this type of policy, we would expect gains in enrollment to be concentrated around areas with local ITES centers; to the extent that one accepts the argument in Section 5, this concentration could be limited by broader information sharing. This is also consistent with the findings in Jensen (2010). An important caveat to this policy argument is that our result hinge on the fact that jobs in ITES centers require

additional education; Atkin (2009) finds that growth in the export sector in Mexico actually leads to school dropout since export jobs pay well but do not require schooling. 


\section{References}

Alderman, Peter F. Orazem Harold and Elizabeth M. Paterno, "School Quality, School Cost, and the Public/Private School Choices of Low-Income Households in Pakistan," Journal of Human Resources, 2001, 36 (2), 304-326.

Atkin, David, "Endogenous Skill Acquisition and Export Manufacturing in Mexico," mimeo, Yale University, 2009.

Burde, Dana and Leigh L. Linden, "The Effect of Proximate Schools: A Randomized Controlled Trial in Afghanistan," Mimeo, Columbia University, December 2009.

Chaudhury, F. Halsey Rogers Karthik Muralidharan Michael Kremer Nazmul and Jeffrey Hammer, "Teacher Absence in India: A Snapshot," Journal of the European Economic Association, 2005, 3 (2-3).

Dossani, Rafiq and Martin Kenney, "The Next Wave of Globalization? Exploring the Relocation of Service Provision to India," Working Paper 156, 2004.

Duflo, Esther, "Schooling and Labor Market Consequences of School Construction in Indonesia: Evidence from an Unusual Policy Experiment," American Economic Review, 2001, 91 (4).

, Rema Hanna, and Stephen Ryan, "Monitoring Works: Getting Teachers to Come to School," Mimeo, MIT, 2009.

Evans, David, Michael Kremer, and Muthoni Ngatia, "The Impact of Distributing School Uniforms on Children's Education in Kenya," mimeo, World Bank, 2008.

Foster, Andrew and Mark Rosenzweig, "Technical Change and Human Capital Returns and Investments: Evidence from the Green Revolution," American Economic Review, 1996, 86 (4), 931-953.

Freeman, Richard, The Overeducated American, New York: Academic Press, 1976.

Glewwe, Paul and Hanan G. Jacoby, "Economic growth and the demand for education: is there a wealth effect?," Journal of Development Economics, 2004, 74 (1), 33-51.

Glick, Peter and David E. Sahn, "Schooling of girls and boys in a West African country: the effects of parental education, income, and household structure," Economics of Education Review, 2000, 19, 63-87.

Griliches, Zvi, "Education, Human Capital, and Growth: A Personal Perspective," Journal of Labor Economics, 1997, 15, S330-S344.

Heckman, James, Private Sector Skill Formation: International Comparisons, University of Chicago Press, 1993.

Jensen, Robert, "Economic Opportunities and Gender Differences in Human Capital: an Experimental Test for India," Mimeo, UCLA, 2010.

_ _ "The (Perceived) Returns to Education and the Demand for Schooling," Quarterly Journal of Economics, Forthcoming. 
_ and Emily Oster, "The Power of TV: Cable Television and Women's Status in India," Quarterly Journal of Economics, 2009, 124 (3), 465-476.

Kane, Thomas, "College Entry by Blacks since 1970: The Role of College Costs, Family Background and the Returns to Education," Journal of Political Economy, 1994, 102 (5), 878-911.

Katz, Lawrence and Kevin Murphy, "Changes in Relative Wages, 1963-1987: Supply and Demand Factors," Quarterly Journal of Economics, 1992, 107 (1), 35-78.

Kremer, Michael, "Randomized Evaluations of Educational Programs in Developing Countries: Some Lessons," American Economic Review, 2003, 92 (2).

LaFerrara, Eliana, Alberto Chong, and Suzanne Duryea, "Soap Operas and Fertility: Evidence from Brazil," mimeo, University of Bocconi, 2009.

Miguel, Edward and Michael Kremer, "Worms: Identifying Impacts on Education and Health in the Presence of Treatment Externalities," Econometrica, 2004, 72 (1), 159-217.

Mirchandani, Kiran, "Practices of Global Capital: gaps, cracks, and ironies in transnational call centres in India," Global Networks, 2004, 4 (4), 355-373.

Munshi, Kaivan and Mark Rosenzweig, "Traditional Institutions Meet the Modern World: Caste, Gender, and Schooling Choice in a Globalizing Economy," American Economic Review, 2006, 96 (4).

NASSCOM, "Strategic Review 2004," New Delhi: National Association of Software and Service Companies, 2004, pp. 185-194.

_ , "Strategic Review 2010," New Delhi: National Association of Software and Service Companies, 2010 .

Ng, Cecelia and Swasti Mitter, "Valuing Women's Voices: Call Center Workers in Malaysia and India," Gender and Technology Development, 2005, 9, 209-233.

Noronha, Ernesto and Premilla D'Cruz, "Engaging the professional: organising call centre agents in India," Industrial Relations Journal, 2009, 40 (3), 215-234.

Orazem, Peter and Elizabeth M. King, "Schooling in Developing Countries: The Roles of Supply, Demand and Government Policy," Iowa State University, Department of Economics Working Paper 07019, 2007.

Schultz, Paul, "School Subsidies for the Poor: Evaluating the Mexican PROGRESA Poverty Program," Journal of Development Economics, 2004, 74 (1), 199-250.

Shastry, Gauri Kartini, "Human Capital Response to Globalization: Education and Information Technology in India," mimeo, Wellesley College, 2010.

World Bank, World Development Indicators 2009, The World Bank, 2009. 
Figure 1:

Distribution of ITES Center Founding Dates

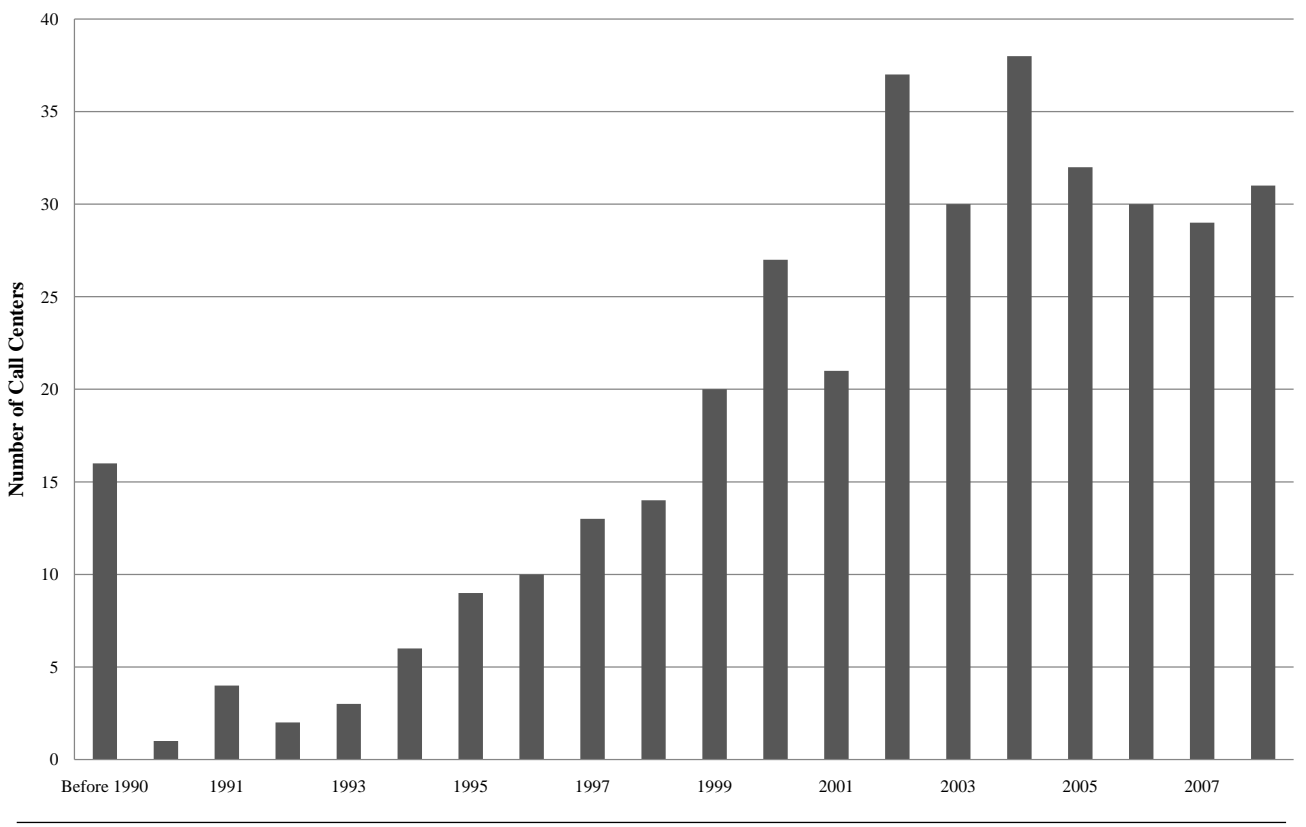

Notes: This figure shows the distribution of ITES center founding dates among centers in our sample.

Figure 2:

Impact of ITES Centers on School Enrollment

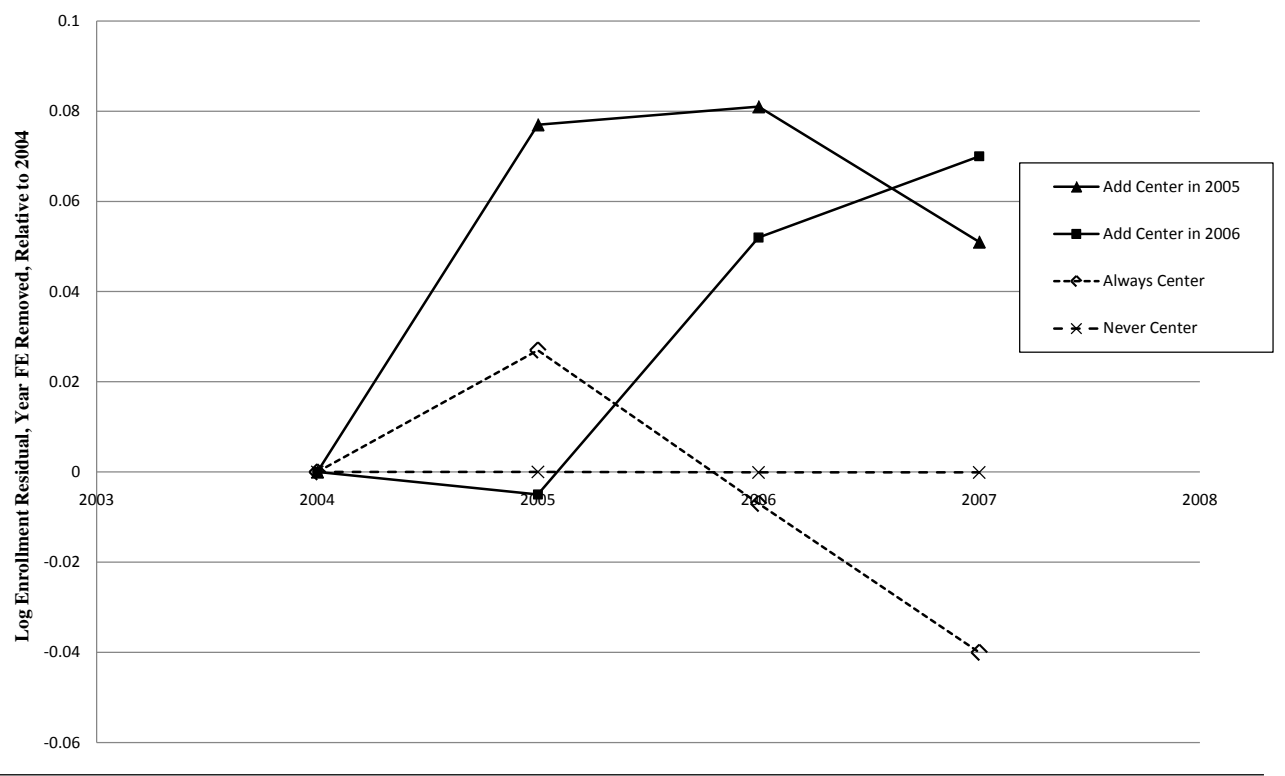

Notes: This figure shows changes in enrollment over time for four balanced panels of schools. All enrollment numbers are residuals from a regression of log enrollment on year enrollment is recorded as of September 2004. Schools are coded as adding a center in 2005 if an ITES center is founded in the area any time during 2005. 
Table 1: DISE Summary Statistics

\begin{tabular}{lccc}
\hline \multicolumn{4}{c}{ Panel A: Years of Coverage and Number of Schools } \\
\hline \hline & Andhra Pradesh & Karntaka & Tamil Nadu \\
\hline Years of Data Coverage & $2004-2007$ & $2001-2007$ & $2003-2007$ \\
Number of Schools in: & & \\
2001-02 & & 27,136 & \\
$2002-03$ & & 43,409 & \\
$2003-04$ & 59,121 & 44,636 & 43,662 \\
2004-05 & 89,474 & 48,515 & 48,391 \\
2005-06 & 99,017 & 50,889 & 48,283 \\
2006-07 & 98,485 & 52,369 & 50,696 \\
2007-08 & Mean & Std. Dev. & Observations \\
\hline \multicolumn{4}{c}{ Panel B: School Summary Statistics } \\
\hline \hline Total Enrollment & 143.8 & 166.4 & 905,838 \\
Grade 1 Enrollment & 40.0 & 47.3 & 905,838 \\
Grade 3 Enrollment & 38.5 & 47.6 & 905,838 \\
Grade 5 Enrollment & 37.6 & 49.7 & 905,838 \\
Grade 7 Enrollment & 27.7 & 67.6 & 905,838 \\
Girl Enrollment & 69.4 & 88.9 & 905,838 \\
Boy Enrollment & 74.4 & 96.4 & 905,838 \\
\% Classrooms in Good Condition & 70.7 & 37.2 & 905,838 \\
\% Schools with Electricity & 49.0 & 50.0 & 905,838 \\
\% Schools with Boundary Walls & 51.3 & 50.0 & 905,838 \\
Teach in English (0/1) & 0.11 & 0.32 & 905,717 \\
Total School-Age Population & 163.1 & 1,404 & 255,355 \\
\hline
\end{tabular}

Notes: Panel A shows years of data coverage and summary statistics by state for the three states in our data set. Panel B shows summary statistics on enrollment and school characteristics for the sample of schools used in the analysis. Population is recorded by the schools for only a subset of schools and years. 
Table 2: ITES Center Summary Statistics

\begin{tabular}{|c|c|c|}
\hline \multicolumn{3}{|c|}{ Panel A: Number of ITES Centers By State } \\
\hline & \multicolumn{2}{|c|}{ Number of ITES Centers } \\
\hline & Including Cities & Excluding Cities \\
\hline Andhra Pradesh & 100 & 74 \\
\hline Karnataka & 144 & 121 \\
\hline Tamil Nadu & 157 & 65 \\
\hline \multicolumn{3}{|c|}{ Panel B: Number of ITES Centers by Pin Code } \\
\hline & \multicolumn{2}{|c|}{ Number of Pin Codes } \\
\hline Number of ITES Centers & Including Cities & Excluding Cities \\
\hline 0 & 5,219 & \\
\hline 1 & 68 & 47 \\
\hline 2 & 29 & 22 \\
\hline 3 & 12 & 10 \\
\hline 4 & 11 & 8 \\
\hline $5+$ & 25 & 5 \\
\hline \multicolumn{3}{|c|}{ Panel C: Number of Schools by Category } \\
\hline \multicolumn{3}{|c|}{$\begin{array}{l}\text { Number of Schools } \\
\end{array}$} \\
\hline Never had a ITES Center & \multicolumn{2}{|c|}{238,986} \\
\hline Has Same Number of ITES Centers & \multicolumn{2}{|c|}{172} \\
\hline Has Change in Number of ITES Centers & \multicolumn{2}{|c|}{408} \\
\hline \multicolumn{3}{|c|}{ Panel D: ITES Center Survey Results $(n=281)$} \\
\hline Median Number of Employees & \multicolumn{2}{|c|}{80} \\
\hline Median Age & \multicolumn{2}{|c|}{28} \\
\hline Share with Voice Employees & \multicolumn{2}{|c|}{.658} \\
\hline Share with English Voice Employees & \multicolumn{2}{|c|}{.658} \\
\hline Share Employees with Children & \multicolumn{2}{|c|}{.098} \\
\hline Share Employees Relocated for Work & \multicolumn{2}{|c|}{.116} \\
\hline
\end{tabular}

Notes: This table shows summary statistics for our sample of ITES centers. Location (PIN code) and founding year were collected in a primary survey; only centers with both location and founding date were included in the sample. Panel D reports data from a phone survey which covered $70 \%$ of these centers and asked more detailed questions on employees and services. 
Table 3: Placement of ITES Centers

\begin{tabular}{lcc|cc}
\hline Dependent Variable: & \multicolumn{2}{c|}{ Number of ITES Centers, 2007 } & \multicolumn{2}{c}{ Add ITES Center During Sample } \\
\hline \hline Ever Had Electricity & $(1)$ & $(2)$ & $(3)$ & $(4)$ \\
& -.0002 & -.0001 & -.0002 & .0001 \\
Urban & $(.0005)$ & $(.0005)$ & $(.0003)$ & $(.0003)$ \\
& $.010^{* * *}$ & $.010^{* * *}$ & $.004^{* * *}$ & $.004^{* * *}$ \\
Any English School $(0 / 1)$ & $(.001)$ & $(.001)$ & $(.001)$ & $(.001)$ \\
& $.007^{* * *}$ & $.006^{* * *}$ & $.003^{* * *}$ & $.003^{* * *}$ \\
Log Enroll. First Survey Year & $(.0008)$ & $(.0008)$ & $(.0004)$ & $(.0004)$ \\
& -.00005 & -.0001 & .000001 & -.0001 \\
& $(.0001)$ & $(.0002)$ & $(.0001)$ & $(.0001)$ \\
\hline State Fixed Effects & NO & YES & NO & YES \\
\hline R-squared & 0.002 & 0.003 & .002 & .002 \\
Observations & 71,667 & 71,667 & 71,890 & 71,890 \\
\hline
\end{tabular}

Notes: This table shows the effects of village characteristics on ITES center placement. The left hand side variable in Columns (1) and (2) is the number of ITES centers in 2007; in Columns (3) and (4) it is whether any centers were added during the sample period. Standard Errors in Parentheses, clustered at the village level. ${ }^{*}$ significant at $10 \%{ }^{* *}$ significant at $5 \%{ }^{* * *}$ significant at $1 \%$ 
Table 4: Effect of ITES Centers on School Enrollment

\begin{tabular}{|c|c|c|c|c|}
\hline Dependent Variable: & \multicolumn{4}{|c|}{ Log Enrollment } \\
\hline \multicolumn{5}{|c|}{ Panel A: Number of ITES Centers in PIN Code } \\
\hline \multirow[t]{2}{*}{ Sample: } & \multicolumn{2}{|c|}{ All Schools } & In Village with Any & Ever Had an \\
\hline & & & English Schools & ITES Center \\
\hline \multirow[t]{2}{*}{ Controls: } & Standard & District Trends & Standard & Standard \\
\hline & $(1)$ & $(2)$ & $(3)$ & $(4)$ \\
\hline \multirow[t]{2}{*}{ Number of ITES Centers } & $.057^{* *}$ & $.043^{* * *}$ & $.070^{* *}$ & $.109^{* * *}$ \\
\hline & $(.024)$ & $(.015)$ & $(.028)$ & $(.035)$ \\
\hline \multirow[t]{2}{*}{ Observations } & 918,136 & 918,136 & 276,044 & 2,123 \\
\hline & \multicolumn{4}{|c|}{ Panel B: Any ITES Center in PIN Code } \\
\hline \multirow[t]{2}{*}{ Sample: } & \multirow{2}{*}{\multicolumn{2}{|c|}{ All Schools }} & In Village with Any & Ever Had an \\
\hline & & & English Schools & ITES Center \\
\hline \multirow[t]{2}{*}{ Controls: } & Standard & District Trends & Standard & Standard \\
\hline & $(1)$ & $(2)$ & $(3)$ & $(4)$ \\
\hline \multirow[t]{2}{*}{ Any ITES Center } & $.055^{*}$ & $.034^{* *}$ & $.070^{*}$ & .108 \\
\hline & $(.034)$ & $(.017)$ & $(.041)$ & $(.066)$ \\
\hline Observations & 918,136 & 918,136 & 276,044 & 2,123 \\
\hline \multicolumn{5}{|c|}{ Panel C: Number of ITES Centers in Neighboring PIN Codes } \\
\hline Sample: & \multicolumn{2}{|c|}{ All Schools } & In Village with Any & Ever Had an \\
\hline \multirow{3}{*}{ Controls: } & & & & \\
\hline & Standard & District Trends & Standard & Standard \\
\hline & $(1)$ & $(2)$ & $(3)$ & $(4)$ \\
\hline \multirow[t]{2}{*}{ ITES Centers in Village } & $.052^{* *}$ & $.039^{* * *}$ & $.063^{* * *}$ & $.099^{* *}$ \\
\hline & $(.026)$ & $(.015)$ & $(.023)$ & $(.039)$ \\
\hline \# ITES Centers in 1st, 2nd & $.037^{* * *}$ & $.039^{* * *}$ & $.048^{* * *}$ & .064 \\
\hline Nearest Neighbors & $(.013)$ & $(.011)$ & $(.012)$ & $(.079)$ \\
\hline \# ITES Centers in 3rd-5th & .013 & .008 & .019 & $-.038^{* *}$ \\
\hline Nearest Neighbors & $(.013)$ & $(.009)$ & $(.012)$ & .017 \\
\hline Observations & 918,136 & 918,136 & 276,044 & 2,123 \\
\hline \multicolumn{5}{|c|}{$\begin{array}{l}\text { Standard controls: School fixed effects, time-varying school plant characteristics, year } \\
\text { dummies interacted with dummies for state, urban, and English language school in village. } \\
\text { District Trend Controls: Standard controls plus district-specific trends. }\end{array}$} \\
\hline
\end{tabular}

Notes: This table shows our primary estimates of the impact of ITES centers on school enrollment. The independent variable measures the number of ITES centers in the same PIN code as the school. Columns 1-2 include all schools. Column 3 is limited to villages with any English schools. Column 4 is limited to schools which ever have an ITES center in their PIN code (either always have the same number or change during the sample). Standard Errors in Parentheses. ${ }^{*}$ significant at $10 \%^{* *}$ significant at $5 \%^{* * *}$ significant at $1 \%$. Standard errors are clustered at the village level in Columns (1), (3) and (4); clustered errors could not be estimated when district trends are included in Column (2). 
Table 5: Effects of Pretrends

\begin{tabular}{|c|c|c|c|c|}
\hline Dependent Variable: & \multicolumn{4}{|c|}{ Log Enrollment } \\
\hline \multicolumn{5}{|c|}{ Panel A: Number of ITES Centers Next Year } \\
\hline Sample: & \multicolumn{2}{|c|}{ All Schools } & In Village with Any & Ever Had an \\
\hline \multirow[t]{2}{*}{ Controls: } & Standard & District Trends & Standard & Standard \\
\hline & (1) & $(2)$ & (3) & $(4)$ \\
\hline \multirow[t]{2}{*}{ ITES Centers } & $.054^{*}$ & $.040^{* *}$ & $.065^{* *}$ & $.099^{* *}$ \\
\hline & $(.028)$ & $(.018)$ & $(.033)$ & $(.042)$ \\
\hline \multirow[t]{2}{*}{ ITES Centers Next Year } & .006 & .005 & .007 & .018 \\
\hline & $(.018)$ & $(.017)$ & $(.020)$ & $(.024)$ \\
\hline $\mathrm{p}$-value, This Year $=$ Next & 0.234 & 0.261 & 0.207 & 0.163 \\
\hline Observations & 918,136 & 918,136 & 276,044 & 2,123 \\
\hline \multicolumn{5}{|c|}{ Panel B: Trends Leading Up to ITES Center Entry } \\
\hline \multirow[t]{2}{*}{ Sample: } & \multirow{2}{*}{\multicolumn{2}{|c|}{ All Schools }} & In Village with Any & Ever Had an \\
\hline & & & English Schools & ITES Center \\
\hline \multirow[t]{2}{*}{ Controls: } & Standard & District Trends & Standard & Standard \\
\hline & (1) & $(2)$ & (3) & (4) \\
\hline \multirow[t]{2}{*}{ ITES Centers } & $.063^{* * *}$ & $.060^{*}$ & $.068^{* * *}$ & $.084^{* * *}$ \\
\hline & $(.019)$ & $(.032)$ & $(.020)$ & $(.027)$ \\
\hline \multirow[t]{2}{*}{ Years Until Entry } & .002 & .005 & -.0004 & -.008 \\
\hline & $(.007)$ & $(.008)$ & $(.009)$ & $(.013)$ \\
\hline Observations & 918,136 & 918,136 & 276,044 & 2,123 \\
\hline \multicolumn{5}{|c|}{$\begin{array}{l}\text { Standard controls: School fixed effects, time-varying school plant characteristics, year } \\
\text { dummies interacted with dummies for state, urban, and English language school in village. } \\
\text { District Trend Controls: Standard controls plus district-specific trends. }\end{array}$} \\
\hline
\end{tabular}

Notes: This table tests whether there are pre-trends in the data: do future ITES centers predict current enrollment? The independent variable in Panel A measures the number of ITES centers in the same PIN code as the school either in the current year or the following year. The independent variable in Panel B measured the number of ITES centers in the same PIN code as the school, along with the linear trend in enrollment leading up to the entry of an ITES center. Columns 1-2 include all schools. Column 3 is limited to villages with any English schools. Column 4 is limited to schools which ever have an ITES center in their PIN code (either always have the same number or change during the sample). Standard Errors in Parentheses. ${ }^{*}$ significant at $10 \%$ ${ }^{* *}$ significant at $5 \%^{* * *}$ significant at $1 \%$. Standard errors are clustered at the village level in Columns (1), (3) and (4); clustered errors could not be estimated when district trends are included in Column (2). 
Table 6: Effects by Language of Instruction

\begin{tabular}{|c|c|c|c|c|}
\hline \multirow{2}{*}{$\begin{array}{l}\text { Dependent Variable: } \\
\text { Sample: }\end{array}$} & \multicolumn{4}{|c|}{ Log Enrollment } \\
\hline & \multicolumn{2}{|c|}{ All Schools } & $\begin{array}{l}\text { In Village with Any } \\
\text { English Schools }\end{array}$ & $\begin{array}{l}\text { Ever Had an } \\
\text { ITES Center }\end{array}$ \\
\hline \multicolumn{5}{|c|}{ Panel A: Impact of ITES Centers by School Language of Instruction } \\
\hline Controls: & Standard & District Trends & Standard & Standard \\
\hline \# Centers $\times$ Local Lang. & $\begin{array}{l}-.011 \\
(.022)\end{array}$ & $\begin{array}{l}-.023 \\
(.019)\end{array}$ & $\begin{array}{l}-.014 \\
(.030)\end{array}$ & $\begin{array}{c}.030 \\
(.037)\end{array}$ \\
\hline \# Centers $\times$ English & $\begin{array}{l}.149^{* * *} \\
(.039)\end{array}$ & $\begin{array}{l}.133^{* * *} \\
(.022)\end{array}$ & $\begin{array}{l}.149^{* * *} \\
(.038)\end{array}$ & $\begin{array}{l}.213^{* * *} \\
(.048)\end{array}$ \\
\hline p-value, English=Local Language & 0.000 & 0.000 & 0.001 & 0.001 \\
\hline Observations & 918,014 & 918,014 & 275,981 & 2,121 \\
\hline \multicolumn{5}{|c|}{ Panel B: Impact of ITES Centers by Detailed School Language of Instruction } \\
\hline Controls: & Standard & District Trends & Standard & Standard \\
\hline \# Centers $\times$ Local Lang. & $\begin{array}{l}-.011 \\
(.022)\end{array}$ & $\begin{array}{l}-.023 \\
(.019)\end{array}$ & $\begin{array}{l}-.014 \\
(.030)\end{array}$ & $\begin{array}{l}.033 \\
(.037)\end{array}$ \\
\hline \# Centers $\times$ Some English & $\begin{array}{l}.129^{* *} \\
(.058)\end{array}$ & $\begin{array}{l}.118^{* * *} \\
(.038)\end{array}$ & $\begin{array}{l}.125^{* *} \\
(.058)\end{array}$ & $\begin{array}{l}.181^{* * *} \\
(.061)\end{array}$ \\
\hline \# Centers $\times$ All English & $\begin{array}{l}.160^{* * *} \\
(.044)\end{array}$ & $\begin{array}{l}.142^{* * *} \\
(.028)\end{array}$ & $\begin{array}{l}.162^{* * *} \\
(.043)\end{array}$ & $\begin{array}{l}.235^{* * *} \\
(.053)\end{array}$ \\
\hline Observations & 918,014 & 918,014 & 275,981 & 2,121 \\
\hline \multicolumn{5}{|c|}{ Panel C: Impact of Voice and All ITES Centers by School Language of Instruction } \\
\hline Controls: & Standard & District Trends & Standard & Standard \\
\hline \# Non-Voice $\times$ Local Lang. & $\begin{array}{l}.091^{* *} \\
(.040)\end{array}$ & $\begin{array}{l}.094^{*} \\
(.056)\end{array}$ & $\begin{array}{l}.099^{*} \\
(.053)\end{array}$ & $\begin{array}{l}.128^{* * *} \\
(.036)\end{array}$ \\
\hline \# Non-Voice $\times$ English & $\begin{array}{l}.124^{* * *} \\
(.009)\end{array}$ & $\begin{array}{l}.104^{* * *} \\
(.039)\end{array}$ & $\begin{array}{l}.139^{* * *} \\
(.010)\end{array}$ & $\begin{array}{l}.182^{* * *} \\
(.061)\end{array}$ \\
\hline \# Voice $\times$ Local Lang. & $\begin{array}{l}-.036^{*} \\
(.021)\end{array}$ & $\begin{array}{c}-.056^{* *} \\
(.023)\end{array}$ & $\begin{array}{l}-.051^{*} \\
(.027)\end{array}$ & $\begin{array}{l}-.019 \\
(.052)\end{array}$ \\
\hline \# Voice $\times$ English & $\begin{array}{l}.164^{* *} \\
(.070)\end{array}$ & $\begin{array}{l}.147^{* * *} \\
(.030) \\
\end{array}$ & $\begin{array}{l}.158^{* *} \\
(.071)\end{array}$ & $\begin{array}{l}.205^{* * *} \\
(.074)\end{array}$ \\
\hline $\begin{array}{l}\text { p-value:V.English - V.Local = } \\
\text { N.V.English-N.V.Local }\end{array}$ & 0.052 & 0.015 & 0.068 & 0.099 \\
\hline Observations & 917,955 & 917,955 & 275,969 & 2,062 \\
\hline $\begin{array}{l}\text { Standard controls: School fixed ef } \\
\text { dummies interacted with dummies } \\
\text { District Trend Controls: Standaro }\end{array}$ & $\begin{array}{l}\text { cts, time-va } \\
\text { or state, ur } \\
\text { controls plu. }\end{array}$ & $\begin{array}{l}\text { rying school plant } \\
\text { ban, and English } \\
\text { district-specific }\end{array}$ & $\begin{array}{l}\text { characteristics, year } \\
\text { inguage school in vill } \\
\text { ends. }\end{array}$ & \\
\hline
\end{tabular}

Notes: This table shows the impact of ITES centers by school language of instruction. Panel A shows the differential effects for English and local language schools. Panel B shows the effect for local language schools, schools with some English instruction, and schools with exclusive English instruction. Panel C shows the effects by school language for voice and non-voice ITES centers. Voice centers are defined as ITES centers where at least half of employees handle voice calls. Columns 1-2 include all schools. Column 3 is limited to villages with any English schools. Column 4 is limited to schools which ever have an ITES center in their PIN code. Standard Errors in Parentheses. ${ }^{*}$ significant at $10 \%{ }^{* *}$ significant at $5 \%^{* * *}$ significant at $1 \%$. Standard errors are clustered at the village level in Columns (1), (3) and (4); clustered errors could not be estimated when district trends are included in Column (2). 
Table 7: Robustness: Number of Schools

\begin{tabular}{lcccc}
\hline Dependent Variable: & \multicolumn{3}{c}{ Count of Schools in Village } \\
\hline Sample: & \multicolumn{2}{c}{ All Schools } & $\begin{array}{c}\text { Villages with Any } \\
\text { English-Language Schools }\end{array}$ & $\begin{array}{c}\text { Ever Had an } \\
\text { ITES Center }\end{array}$ \\
\hline Controls: & Standard & District Trends & Standard & Standard \\
\hline \hline Number of ITES Centers & .007 & .010 & .001 & .014 \\
& $(.053)$ & $(.020)$ & $(.104)$ & $(.092)$ \\
\hline Observations & 356,796 & 356,796 & 32,301 & 477 \\
\hline Standard controls: Village fixed effects, time-varying school plant characteristics, & \\
year dummies interacted with dummies for state, urban, and English language school in village. \\
District Trend Controls: Standard controls plus district-specific trends.
\end{tabular}

Notes: This table shows the effect of ITES centers on number of schools in a village. Columns 1-2 include all schools. Column 3 is limited to villages with any English schools. Column 4 is limited to schools which ever have an ITES center in their PIN code (either always have the same number or change during the sample). Standard Errors in Parentheses. ${ }^{*}$ significant at $10 \%^{* *}$ significant at $5 \%^{* * *}$ significant at $1 \%$. Standard errors are clustered at the village level in Columns (1), (3) and (4); clustered errors could not be estimated when district trends are included in Column (2).

Table 8: Robustness: Income Effects

\begin{tabular}{lcccc}
\hline & $(1)$ & $(2)$ & $(3)$ & $(4)$ \\
\hline Existing Estimates of Income Elasticity & 0.25 & 0.4 & 1 & 1.25 \\
Estimate of \% Change in Income from ITES Introduction & $0.57 \%$ & $0.57 \%$ & $0.57 \%$ & $0.57 \%$ \\
Predicted Percent Increase in Enrollment & $0.14 \%$ & $0.23 \%$ & $0.57 \%$ & $0.72 \%$ \\
Actual Increase in Enrollment & $5.5 \%$ & $5.5 \%$ & $5.5 \%$ & $5.5 \%$ \\
Percent of Actual Enrollment Increase Explained & $2.5 \%$ & $4.2 \%$ & $10.4 \%$ & $13.1 \%$ \\
\hline
\end{tabular}

Notes: Income elasticity estimates from (1) Glewwe and Jacoby (2004), (2) Glick and Sahn (2000), (3) Orazem and King (2007), and (4) Alderman et al. (2001). Appendix A reports details on how we calculate the estimated $\%$ change in income from the ITES introduction. The fourth row reports the percent of the actual enrollment increase explained, not percentage points. 


\section{Appendix Tables}

Appendix Table 1: Enrollment Effects by Demographic Group, State

\begin{tabular}{llccc}
\hline Dependent Variable: & \multicolumn{3}{c}{ Log Enrollment } \\
\hline & & $\begin{array}{c}\text { Number of } \\
\text { ITES Centers }\end{array}$ & $\begin{array}{c}\text { Standard } \\
\text { Error }\end{array}$ & Observations \\
\hline$(1)$ & Boy Enrollment & $.059^{* *}$ & .023 & 902,616 \\
$(2)$ & Girl Enrollment & $.050^{* *}$ & .024 & 907,438 \\
\hline$(3)$ & Grades 1-2 Enrol. & .034 & .027 & 828,895 \\
$(4)$ & Grades 3-4 Enrol. & $.069^{* *}$ & .035 & 817,038 \\
$(5)$ & Grades 5-6 Enrol. & .043 & .029 & 857,209 \\
$(6)$ & Grades 7-8 Enrol. & $.097^{* * *}$ & .030 & 341,845 \\
\hline$(7)$ & Andhra Pradesh & .031 & .045 & 359,150 \\
$(8)$ & Karnataka & .066 & .071 & 317,225 \\
$(9)$ & Tamil Nadu & $.082^{* * *}$ & .028 & 241,761 \\
\hline
\end{tabular}

Notes: This table the coefficient on number of ITES centers from regression of the form in Column 1 of Table 4 but with variation in the left hand side variable. The first six rows show the effect on enrollment for different gender and age demographic groups. The last two three rows divide the sample by state. All regressions include the standard controls: School fixed effects, time-varying school plant characteristics, year dummies interacted with dummies for state, urban, and english language school in village. Standard Errors in Parentheses, clustered at the village level. ${ }^{*}$ significant at $10 \%{ }^{* *}$ significant at $5 \%{ }^{* * *}$ significant at $1 \%$ 
Appendix Table 2: Effects on Enrollment with Population Controls

\begin{tabular}{|c|c|c|c|c|}
\hline Dependent Variable: & \multicolumn{4}{|c|}{ Log Enrollment } \\
\hline \multicolumn{5}{|c|}{ Panel A: Limited Sample, No Population Control } \\
\hline Sample: & \multicolumn{2}{|c|}{ All Schools } & In Village with Any & Ever Had an \\
\hline \multirow[t]{2}{*}{ Controls: } & Standard & District Trends & Standard & Standard \\
\hline & (1) & (2) & (3) & (4) \\
\hline \multirow[t]{2}{*}{ Number of ITES Centers } & $.076^{*}$ & $.054^{* * *}$ & $.092^{*}$ & .137 \\
\hline & $(.043)$ & $(.018)$ & $(.051)$ & $(.126)$ \\
\hline Observations & 327,740 & 327,740 & 120,547 & 1,075 \\
\hline \multicolumn{5}{|c|}{ Panel B: Limited Sample, with Population Control } \\
\hline \multirow[t]{2}{*}{ Sample: } & \multirow{2}{*}{\multicolumn{2}{|c|}{ All Schools }} & In Village with Any & Ever Had an \\
\hline & & & English-Language Schools & ITES Center \\
\hline \multirow[t]{2}{*}{ Controls: } & Standard & District Trends & Standard & Standard \\
\hline & $(1)$ & $(2)$ & $(3)$ & $(4)$ \\
\hline \multirow[t]{2}{*}{ Number of ITES Centers } & $.074^{*}$ & $0.052^{* * *}$ & $.091^{*}$ & .131 \\
\hline & $(.043)$ & $(.018)$ & $(.050)$ & $(.121)$ \\
\hline \multirow[t]{2}{*}{ Log Village Population } & $.006^{* * *}$ & $.006^{* * *}$ & .004 & -.019 \\
\hline & $(.002)$ & $(.0008)$ & $(.003)$ & $(.029)$ \\
\hline Observations & 327,740 & 327,740 & 120,547 & 1,075 \\
\hline \multicolumn{5}{|c|}{$\begin{array}{l}\text { Standard controls: School fixed effects, time-varying school plant characteristics, year } \\
\text { dummies interacted with dummies for state, urban, and english language school in village. } \\
\text { District Trend Controls: Standard controls plus district-specific trends. }\end{array}$} \\
\hline
\end{tabular}

Notes: This table shows the impact of ITES centers controlling for population. Population is reported by a subset of school-years, and is reported by the school as the village population. In cases where the school does not report population but other schools in the village do report population we use the average population among reporter schools as population for all schools in the village. Panel A does not control for population but limit the sample to school-years in which population is observed. Standard Errors in Parentheses.*significant at $10 \%{ }^{* *}$ significant at $5 \%{ }^{* * *}$ significant at $1 \%$ 


\section{Appendix A: Calculating ITES Center Impact on Income}

The second row of Table 8 reports an estimated percentage increase in income due to ITES centers. We use a simple back-of-the-envelope calculation to generate this number. Although this is very unlikely to be perfectly accurate, we argue it's an upper bound on what the impact might be. To generate this number, we focus on the median PIN code and the median ITES center (in terms of size). We observe the number of children enrolled in school in the median PIN code; this number is roughly 10,000. We use this number to estimate the average number of people in the median PIN code. To do this, we note that the Indian census indicates children aged 6-12 make up roughly 15\% of the overall population, and from the National Family and Health Survey (which is consistent with other sources) we observe that roughly $85 \%$ of children in this age range are enrolled in school.

Combining these figures we argue that roughly $12.75 \%$ of individuals are children enrolled in school, so we expect the median income to have roughly 78,000 people.

The median per capita income in these states is $\$ 659$ (Ministry of Statistics and Program Implementation, 2008). Applying this value to the population, we estimate total income of the median PIN code at about $\$ 51$ million.

The median ITES center in our sample has 140 employees and based on a survey of a sub-sample of ITES centers, pays roughly $\$ 2100$ per year in starting wages. This is more than twice the median per capita income. We calculate the increase in income due to ITES centers assuming that the income from ITES center employees is simply added to total income in the PIN code; we note this is likely to be an overestimate, since these individuals probably substitute into ITES center jobs away from some lower paying job, not from doing nothing.

We calculate the increased income, and then calculate the percentage increase implied by this; the resulting figure is $0.57 \%$ as reported in Table 8 . 